\title{
Comparative Study of Morphological Characteristics and Body Composition between Basketball Players from Second Leagues in Montenegro and Serbia
}

\author{
Velisa Vukasevic ${ }^{1}$, Marina Vukotic ${ }^{2}$, Bojan Masanovic ${ }^{2}$ \\ 'Basketball Club Vizura, Belgrade, Serbia, ${ }^{2}$ University of Montenegro, Faculty for Sport and Physical Education, Niksic, Montenegro
}

\begin{abstract}
The purpose of this study was to describe morphological characteristics and body composition of the Second League basketball players from Montenegro and Serbia as well as to make comparation between them. Fortyeight males were enrolled in the study, divided into two groups: twenty-four senior players from the Second Basketball League of Montenegro and twenty-four senior players from the Second Basketball League of Serbia. Morphological characteristics were evaluated by a battery of four variables: body height, body weight, arm span and length of the leg. Body composition were evaluated by a battery of one variables: fat percentage of body. The standard central and dispersive parameters of all variables were calculated. The significance of the differences between the Second League basketball players from Montenegro and Serbia was determined by a t-test for small independent samples. The results showed that a significant differences was no found for any variable among the group. Therefore, these findings may give coaches knowledge that Montenegrin players have a good morphological potential, in that segment are not lagging behind for the Serbian players, whose players make excellent results at international competitions.
\end{abstract}

Key words: Basketball, Morphological Characteristics, Montenegro, Serbia

\section{Uvod}

U svakom sportu i sportskoj disciplini postoje specifičnosti i različitosti u takmičarskoj strukturi, pa se nameće potreba za neprekidnim istraživanjem i potvrđivanjem $\mathrm{u}$ praksi upravo tih specifičnosti (Popovic, Smajic, Joksimovic, \& Masanovic, 2010; Vukotić, Čorluka, Vasiljević, \& Bubanja, 2018). Prilikom opredjeljivanja za sportsku disciplinu, odnosno prilikom izbora sportske discipline, kojom će se pojedinac baviti, tjelesna konstitucija igra značajnu ulogu (Masanovic, Popovic, \& Molnar, 2009; Popovic, Molnar, \& Masanovic, 2010; Masanovic, 2015; Bjelica, \& Fratrić 2011; Bjelica 2013). Vrhunski sportisti u pojedinim sportovima često su izjednačeni međusobno u mnogim za sport rele- vantnim parametrima, karakteristika i sposobnosti (Rogulj, Nazor, Srhoj, \& Božin, 2006). Savremena nauka ima za cilj da poboljša performance elitnih igrača i da omogući što precizniju identifikaciju talenata (Popovic, 2013). Ovaj proces je veoma zahtjevan jer svaki sport iziskuje različitu tjelesnu građu koja sportisti omogućuje maksimalne performance za datu disciplinu (Popovic, 2014). Novija istraživanja antropometrijskih karakteristika idu i korak dalje, ukazujući na to da pripadnici istog sporta imaju specifična obilježja u odnosu na pozicije u timu na kojima igraju (Vasiljević, Bjelica, Popović, \& Gardašević, 2015), i zbog toga utvrđivanje antropometrijskih karakteristika predstavlja jednu od tri najčešće testirane dimenzije sportista (Milanović, Jukić,

Correspondence:

Montenegro B.Masanovic

Gport University of Montenegro, Faculty for Sport and Physical Education, Narodne omladine bb, 81400 Niksic, Montenegro E-mail: bojanma@ac.me 
Vuleta, Šimek, \& Šentija, 2005). Pripadnost sportiste jednoj sportskoj grani podrazumijeva njegov „biotip”, koji mu daje prednost da se bavi baš tim sportom u odnosu na druge (Masanovic, 2008). Utvrđivanje biotipa, odnosno tjelesne kompozicije i konstitucije sportista, važan je faktor u procesu selekcije i izrade modela na osnovu kojeg se programira trenažni process (Mašanovic \& Vukašević, 2009; Popović, Mašanović, Molnar, i Smajić, 2009; Gušić, Popović, Molnar, Mašanović, i Radaković, 2017; Masanovic, Popovic, \& Bjelica, 2018; Vukotic, 2010; Vukotic, 2011; Vukotic, 2018). Bolje upoznavanje antropometrijskih karakteristika, tjelesne kompozicije i konstitucije sportista ima za cilj: upravljanje ovim svojstvima, prilagođavanje sportskog treninga individualnim sposobnostima i mogućnost prognoziranja krajnjih dometa (Mašanović, 2009).

Košarka trenutno spada u najpopularnije sportske igre, što pokazuje i ogroman broj registrovanih igrača širom sveta i veliki broj gledalaca (Vukašević, 2010). Ovo veliko interesovanje za košarku proizilazi iz dinamike, atrakcije i lepote koju "kraljica igara" ima u sebi. Košarka obiluje izuzetnim bogatstvom raznih kretnji. Većina elemenata naročito onih sa loptom su veoma složeni. Za njihovo usvajanje i besprekornu primenu u igri potreban je visok nivo razvijenosti celokupnog motornog aparata (Vukašević, 2010). Morfološke karakteristike su izuzetno značajne za uspeh u košarci. U prostoru morfoloških dimenzija košarkaša definisani su zasebni faktori označeni kao latentne morfološke dimenzije: longitudinalna dimenzionalnost skeleta, transverzalna dimenzionalnost skeleta, masa i volumen tela, Potkožno masno tkivo (Bjelica \& Fratrić, 2011). Svrha morfoloških dimenzija je da se poboljšaju mogućnosti u mnogim sportovima (Carter \& Heath, 1990). Morfološki status vrhunskih sportista su relativno homogeni, zavisnosti od sporta, i mogu biti definisan kao modeli sportistskog postignuća (Mišigoj-Duraković, Matković, \& Medved, 1995). Visina i raspon ruku daju prednost u košarci jer se cilj nalazi na velikoj visini, takođe visina igračima omogućava da lakše dodju do lopte u odbrani i napadu, blokiraju protivnički napad i šut (Popovic, 2014). Tjelesna masa može uticati na brzinu, izdržljivost i snagu. Na kraju, dobro je poznato da masno tkivo može da kompromituje fizičko performance (Strel, 2006; Nikolaidis \& Vassilios-Karydis, 2011), djelujući kao balast kod aktivnosti repetitivnog režima rada smanjuje performanse a povećava potrošnju energije (Ramos-Campo et al., 2014). Interdisciplinarni pristup u svakoj sportskoj disciplini je potreban za sportski razvoj pojedinca, on će mu omogućiti da ispuni zadatke tokom procesa sportskog takmičenja ili sportskog treninga (Abernethy, 2005; Morrow \& James, 2005; Bjelica, Gardasevic, \& Vasiljevic, 2018; Bjelica, 2005, Bjelica, Popovic, \& Gardasevic, 2016a; Bjelica, Popovic, \& Gardasevic, 2016b; Bjelica, Popović, Kezunović, Petković, Jurak, \& Grasgruber, 2012; Bjelica, 2002; Bjelica, 2004; Bjelica, 2006a; Bjelica, 2006b; Bjelica \& Krivokapic, 2010; Bjelica \& Krivokapic, 2011; Bjelica \& Krivokapic, 2012; Gardasevic \& Bjelica, 2013; Gardasevic \& Bjelica, 2014; Gardasevic, Popovic, \& Bjelica, 2016; Masanovic, Vukotic, Bjelica, \& Popovic, 2018; Popovic, Bjelica, Vukotic, \& Masanovic, 2018; Sermaxhaj, Popović, Bjelica, Gardašević, \& Arifi, 2017). Uvidom u trenutno stanje antropoloških karakteristika moguće je dobiti uvid u trenutno stanje sastava tijela, a u slučaju postojanja prekomjerne tjelesne mase i pravovremeno uticati na redukciju masti (Vuleta, Nikolić, \& Krakan, 2011).
Osnovni cilj ovog istraživanja je bio da se utvrde postoje li razlike u nivou morfoloških karakteristika i tjelesne kompozicije između igrača Druge lige Crne Gore i igrača Druge lige Srbije, takođe da se utvrdi da li igrači iz Crne Gore imaju dobar morfološki potencijal, odnosno zaostaju li za igračima iz Srbije koji postižu izuzetno dobre rezultate na navećim međunarodnim takmičenjima.

\section{Metod}

Uzorak ispitanika čini ukupno 48 košarkaša seniorskog uzrasta, podijeljen na dva subuzorka. Prvi subuzorak su činili 24 košarkaša koji nastupaju u Drugoj ligi Crne Gore, prosječne starosti $22.20 \pm 4.24$ godina, dok su drugi subuzorak činili 24 košarkaša koji nastupaju u Drugoj ligi Srbije, prosječne starosti $20.33 \pm 3.88$ godina.

Antropometrijsko istraživanje sprovedeno je uz poštovanje osnovnih pravila i principa vezanih za izbor mjernih instrumenata i tehnike mjerenja koji su standardizovani, prema upustvima Internacionalnog Biološkog Programa. Za potrebe ovog istraživanja izmjerene su četiri varijable morfoloških mjera: visina tijela (ATV), težina tijela (ATM), raspon ruku (ARR), dužina noge $(\mathrm{ADN})$, i jedna varijabla za procjenu tjelesnog sastava tijela: procjenat masnog tkiva (APM). Za antropometrijsko merenje korišćeni su standardizovani merni instrumenti: antropometar po Martinu i vaga. Sve relevantne antropomotoričke dimenzije (osim morfološkog svojstva-raspona ruku koje je izmereno antropometrom u standardnim uslovima) su određene prema standardima internacionalnog biološkog programa. Za procjenu sastava tijela korišćena je tanita vaga, model BC-418MA. Princip rada ove vage je zasnovan na indirektnom mjerenju tjelesnog sastava, bezbjedan električni signal se šalje kroz tijelo preko elektroda smještenih u samostalnu jedinicu. Tanita vaga, zahvaljujući atletskom modu koje posjeduje, omogućava sportistima detaljno praćenje tjelesne težine, zdrastvenog stanja i kondicije, sa svim relevantnim parametrima.

Podaci dobijeni istraživanjem obrađeni su postupcima deskriptivne i komparativne statističke procedure. Za svaku varijablu su obrađeni centralni i disperzioni parametri kao i mjere asimetrije i spljoštenosti. Razlike u morfološkim dimenzijama i sastavu tijela košarkaša koji nastupaju u drugoj ligi Crne Gore i drugoj ligi Srbije utvrđene su primjenom diskriminativne parametrijske procedure, t-testom za male nezavisne uzorke, sa statističkom značajnošću od $\mathrm{p}<0.05$.

\section{Rezultati}

U Tabelama 1 i 2 prikazani su osnovni deskriptivni statistički parametri antropometrijskih varijabli i tjelesnog sastava košarkaša dvije države, gdje su izračunate vrijednosti mjera centralne i disperzione tendencije i to: aritmetička sredina (Mean), standardna devijacija (Std. Dev.), varijansa (Variance), minimalne (Min) i maksimalne (Max) vrijednosti, koeficijenti zakrivljenosti (Skewness) i izduženosti (Kurtosis). Prvo su analizirani centralni i disperzioni parametri varijabli za procjenu morfoloških karakteristika i sastava tijela košarkaša koji nastupaju u drugoj po kvalitetu ligi Crne Gore (Tabela 1.).

$\mathrm{Na}$ osnovu centralnih i disperzionih parametara, vrijednosti skjunisa i kurtozisa može se konstatovati da su sve varijable 
Tabela 1. Centralni i disperzioni parametri varijabli za procjenu morfoloških dimenzija i tjelesnog sastava igrača Druge lige Crne Gore $(\mathrm{N}=24)$

\begin{tabular}{|c|c|c|c|c|c|c|c|c|c|}
\hline & \multirow{2}{*}{ Min } & \multirow{2}{*}{ Max } & \multirow{2}{*}{ Mean } & \multirow{2}{*}{ Std.D. } & \multirow{2}{*}{ Variance } & \multicolumn{2}{|c|}{ Skewness } & \multicolumn{2}{|c|}{ Kurtosis } \\
\hline & & & & & & Stat. & Std.E. & Stat. & Std. E. \\
\hline ATV & 182.00 & 206.00 & 194.88 & 6.84 & 46.810 & -.452 & .472 & -.735 & .918 \\
\hline ATM & 72.00 & 110.00 & 91.75 & 11.24 & 126.457 & -.122 & .472 & -.829 & .981 \\
\hline ARR & 181.00 & 212.00 & 196.42 & 8.75 & 76.688 & -.203 & .472 & -.763 & .981 \\
\hline ADN & 102.00 & 123.00 & 113.96 & 5.38 & 28.998 & -.432 & .472 & -.231 & .981 \\
\hline APM & 7.70 & 16.60 & 12.35 & 2.55 & 6.505 & -.171 & .472 & -.1 .069 & .981 \\
\hline
\end{tabular}

u granicama normalne raspodjele. Vidi se po vrijednostima skjunisa da su sve varijable sa negativnim predznakom, što znači da je većina rezultata desno od srednje vrijednosti, među većim vrijednostima. Negativne vrijednosti kurtozisa kod svih varijabli pokazuju da je raspodjela pljosnatija od normale, što govori da je veliki broj rezultata za ovu varijablu raspoređen oko aritmetičke sredine.

Tabela 2. Centralni i disperzioni parametri varijabli za procjenu morfoloških dimenzija i tjelesnog sastava igrača Druge lige Srbije $(\mathrm{N}=24)$

\begin{tabular}{|c|c|c|c|c|c|c|c|c|c|}
\hline & \multirow{2}{*}{ Min } & \multirow{2}{*}{ Max } & \multirow{2}{*}{ Mean } & \multirow{2}{*}{ Std.D. } & \multirow{2}{*}{ Variance } & \multicolumn{2}{|c|}{ Skewness } & \multicolumn{2}{|c|}{ Kurtosis } \\
\hline & & & & & & Stat. & Std.E. & Stat. & Std. E. \\
\hline ATV & 185.00 & 205.00 & 195.04 & 7.15 & 51.172 & .100 & .472 & -1.503 & .918 \\
\hline ATM & 79.00 & 105.00 & 90.96 & 8.52 & 71.650 & .270 & .472 & -1.144 & .981 \\
\hline ARR & 186.00 & 211.00 & 196.79 & 8.10 & 65.737 & .409 & .472 & -.1 .229 & .981 \\
\hline ADN & 102.00 & 123.00 & 112.92 & 5.79 & 33.558 & .061 & .472 & -.1 .036 & .981 \\
\hline APM & 7.70 & 16.10 & 12.43 & 2.46 & 6.098 & .162 & .472 & -.709 & .981 \\
\hline
\end{tabular}

Na osnovu centralnih i disperzionih parametara, vrijednosti skjunisa i kurtozisa košarkaša koji nastupaju u drugoj po kvalitetu lige Srbije, može se konstatovati da su sve varijable u granicama normalne raspodjele i da su vrijednosti približno slične košarkašima predhodno analizirane grupe. Po vrijednostima skjunisa koje imaju pozitivan predznak, vidimo da je većina rezultata lijevo od srednje vrijednosti, među manjim vrijednostima. Negativne vrijednosti kurtozisa kod svih varijabli pokazuju da je raspodjela pljosnatija od normale, što govori da je veliki broj rezultata za ovu varijablu raspoređen oko aritmetičke sredine. Da bi se moglo utvrditi da li ima statistički značajne razlike u analiziranim varijablama kod drugoligaških košarkaša ove dvije zemlje, primjenjena je statistička procedura t-test (Tabela 3).

Tabela 3. Vrijednosti t-testa izmedju aritmetičkih sredina varijabli za procjenu morfoloških dimenzija i tjelesnog sastava igrača Druge lige Crne Gore $(\mathrm{N}=24)$ i Druge lige Srbije $(\mathrm{N}=24)$

\begin{tabular}{|c|c|c|c|c|c|c|c|}
\hline Varijable & Lige & Mean & Std. D. & Std. E. M. & t-test & Sig. & $\begin{array}{c}\text { Mean } \\
\text { Difference }\end{array}$ \\
\hline \multirow{2}{*}{ ATV } & Crna Gora & 194.88 & 6.842 & 1.397 & \multirow{2}{*}{-0.82} & \multirow{2}{*}{.478} & \multirow{2}{*}{-.167} \\
\hline & Srbija & 195.04 & 7.153 & 1.460 & & & \\
\hline \multirow{2}{*}{ ATM } & Crna Gora & 91.75 & 11.245 & 2.295 & \multirow{2}{*}{.275} & \multirow{2}{*}{.231} & \multirow{2}{*}{-.792} \\
\hline & Srbija & 90.96 & 8.524 & 1.740 & & & \\
\hline \multirow{2}{*}{ ARR } & Crna Gora & 196.43 & 8.757 & 1.788 & \multirow{2}{*}{-.152} & \multirow{2}{*}{.899} & \multirow{2}{*}{-.375} \\
\hline & Srbija & 196.79 & 8.108 & 1.655 & & & \\
\hline \multirow{2}{*}{ ADN } & Crna Gora & 113.96 & 5.385 & 1.099 & \multirow{2}{*}{.645} & \multirow{2}{*}{.434} & \multirow{2}{*}{1.042} \\
\hline & Srbija & 112.92 & 5.793 & 1.793 & & & \\
\hline \multirow{2}{*}{ APM } & Crna Gora & 12.35 & 2.550 & 2.551 & \multirow{2}{*}{-.151} & \multirow{2}{*}{.533} & \multirow{2}{*}{-.083} \\
\hline & Srbija & 12.43 & 2.469 & 2.469 & & & \\
\hline
\end{tabular}

$\mathrm{Na}$ osnovu dobijenih vrijednosti rezultata t-testa, može se primijetiti da ne postoje statistički značajne razlike na nivou značajnosti $\mathrm{p}<0.05$. što pokazuje dobru slektiranost igrača Druge lige Crne Gore u odnosu na igrače Druge lige Srbije.

\section{Diskusija}

Rezultati predhodnih istraživanja ukazuju da košarkaše karakteriše velika tjelesna visina, značajno viša od prosjeka opšte populacije. Razlog tome su uslovi igre, potreba da lopta stalno bude podignuta iznad glave (Guarav, 2010), velika visina na kojoj se nalazi odbruč i takođe potreba da se nadvisi protivnik. Prednost visokih igrača je mogućnost da šutiraju sa kraće distance, da imaju viši dohvat u skoku za loptom a takođe i u bloku. Tako na primjer, prosječna visina profesionalnih košarkaša Slovenije koji su pobijedili na posljednjem evropskom prvenstvu bila je $199.5 \mathrm{~cm}$, dok je prosječna visina drugoplasirane i trećeplasirane ekipe prelazila dva metra.

Osnovni cilj ovog istraživanja je bio da se utvrde postoje li razlike u morfološkim karakteristika i sastavu tijela između igrača koji nastupaju u drugom po kvalitetu takmicarskom rangu Crne Gore i igrača koji nastupaju u drugom po kvalitetu takmicarskom rangu Srbije. Takođe da se utvrdi da li igrači iz Crne Gore imaju dobar morfološki potencijal, odnosno zaostaju li morfološkim karakteristikama za igračima iz Srbije 
koji postižu značajnije rezultate na navećim međunarodnim takmičenjim. Uzorak od ukupno 48 ispitanika je podijeljen na dva subuzorka. Prvi subuzorak ispitanika su činila 24 igrača iz Crne Gore prosječne starosti 22.20 \pm 4.24 godine, dok su drugi subuzorak činila 24 igrača iz Srbije prosječne $20.33 \pm 3.88$ godina. Rezultati su dobijeni praćenjem pet varijabli u prostoru morfoloških dimenzija i tjelesnog sastava. Uvidom u dobijene parametre se može zaključiti da se radi o profesionalnim sportistima. Vidi se da su igrači obje lige približnih srednjih vrijednosti analiziranih varijabli, što ne čudi jer se radi o igračima najkvalitetnijih timova pomenutog ranga takmičenja u Crnoj Gori i Srbiji gdje je velika koncetracija kvalitetnih igrača. Takođe prosječna tjelesna visina igrača obije lige značajno je viša od prosjeka populacije izmjerenog na teritoriji Crne Gore i Srbije (Popović, Bjelica, Molnar, Jakšić, \& Akpinar, 2013; Popovic, 2017). Zaključujemo da je selekcija dobro obavljena, što takodje nije iznenadjenje s obzirom da je gustina veoma visokih subjekata karakteristična za ovaj region, pošto je izmjereno da $28 \%$ ispitanika opšte populacije dostiže visinu od $190 \mathrm{~cm}$ ili više (Bjelica, Popović, Kezunović, Petković, Jurak, \& Grasgruber, 2012; Popović, Bjelica, Tanase, i Milašinović, 2015; Popović, Bjelica, Georgijev, Krivokapić, \& Milašinović, 2017; Popovic, 2016; Popovic, 2017). Vrijednosti dobijene t-testom, pokazuju nam da ne postoje statistički značajne razlike između subuzoraka ni kod jednog od izmjerenih parametara. To nam pokazuje dobru slektiranost igrača iz Crne Gore, i navodi nas da zaključimo kako crnogorski igrači posjeduju dobar morfološki potencijal. Ne zaostaju morfološkim karakteristikama za igračim Srbije koji postižu značajne rezultate na najvećim međunarodnim takmičenjima. $\mathrm{Na}$ osnovu toga možemo zaključiti da razloge zbog čega su rezultati selekcija i timova Crne Gore nešto slabiji u odnosu na rezultate selekcija i timova iz Srbije treba tražiti kod nekih drugih parametara od kojih takođe zavisi uspjeh.

Rezultati koji su dobijeni ovim istraživanjem mogu poslužiti kao modelni parametri u procjenjivanim varijablama za sve ostale igrače istog ranga takmičenja u Crnoj Gori i Srbiji, jer su analizirani igrači članovi najkvalitetnijih timova. Treba napomenuti da igrači koje žele uspješno nastupati u ligama gdje se igra najkvalitetnija košarka, moraju imati karakteristike utvrđene standardima za taj sport, a to se prije svega ogleda u morfološkim dimenzijama i tjelesnom sastavu.

\section{Acknowledgements}

There are no acknowledgements.

\section{Conflict of Interest}

The authors declare that there are no conflict of interest.

Received: 01 May 2018| Accepted: 16 June 2018 | Published: 13 July 2018

\section{References}

Abernethy, B. (2005). The biophysical foundations of human movement. Champaign, IL: Human Kinetics.

B. Morrow, J., \& James, R. (2005). Measurement and evaluation in human performance. Champaign, IL: Human Kinetics.

Bjelica, D. (2002). Opšti pojmovi sportskog treninga: (skraćena verzija). Podgorica: Crnogorska sportska akademija.

Bjelica, D. (2004). Uticaj sportskog treninga na antropomotoričke sposobnosti: (fudbalskih kadeta Crne Gore). Podgorica: Crnogorska sportska akademija.

Bjelica, D. (2005). Sistematizacija sportskih disciplina i sportski trening. Podgorica: Crnogorska sportska akademija.

Bjelica, D. (2006a). Sportski trening. Podgorica: Crnogorska sportska akademija.

Bjelica, D. (2006b). Teorijske osnove tjelesnog i zdrastvenog obrazovanja. Pod- gorica: Crnogorska sportska akademija.

Bjelica, D. (2013). Teorija sportskog treninga. Podgorica: Univerzitet Crne Gore.

Bjelica, D., \& Fratrić, F. (2011). Sportski trening: teorija, metodika i dijagnostika. Nikšić: Fakultet za sport i fizičko vaspitanje.

Bjelica, D., Gardasevic, J., \& Vasiljevic, I. (2018). Differences in the morphological characteristics and body composition of football players FC Sutjeska and FC Mladost in Montenegro. Journal of Anthropology of Sport and Physical Education, 2(2), 31-5. doi: 10.26773/jaspe.180406

Bjelica, D., i Krivokapić D. (2012). Uticaj fizičkog vježbanja na psihomotorne funkcije starijih osoba. Zbornik radova Druge međunarodne konferencije Sportske nauke izdravlje, Banja Luka: Panaevropski univerzitet APEIRON, 191-6.

Bjelica, D., i Krivokapić, D. (2010). Teorijske osnove fizičke kulture. Nikšić: Fakultet za sport i fizičko vaspitanje Univerziteta Crne Gore.

Bjelica, D., i Krivokapić, D. (2011). Teorija igre. Nikšić: Fakultet za sport i fizičko vaspitanje Univerziteta Crne Gore.

Bjelica, D., Popović, S., i Gardašević, J. (2016a). Modeli fizičke pripreme vrhunskih sportaša i doziranje opterećenja. Zbornik radova 14. godišnje međunarodne konferencije "Kondicijska priprema sportaša" (185-189), Zagreb: Udruga kondicijskih trenera Hrvatske.

Bjelica, D., Popović, S., i Gardašević, J. (2016b). Opći principi planiranja i programiranja fizičkih priprema sportaša. Zbornik radova 14. godišnje međunarodne konferencije "Kondicijska priprema sportaša" (190-192), Zagreb: Udruga kondicijskih trenera Hrvatske.

Bjelica, D., Popović, S., Kezunović, M., Petković, J., Jurak, G., \& Grasgruber, P. (2012). Body Height and Its Estimation Utilizing Arm Span Measurements in Montenegrin Adults Anthropological Notebooks, 18(2), 69-83.

Carter, J.E.L., \& Heath, B.H. (1990). Somatotyping-Development and application. Cambridge, United Kingdom: Cambridge University Press.

Gardašević, J., i Bjelica, D. (2013). Efekti programiranog trenažnog rada u trajanju od šest nedjelja na transformaciju fleksibilnosti kod fudbalera kadetskog uzrasta. Sport Mont, 11(37-39), 212-7.

Gardašević, J., i Bjelica, D. (2014). Efekti rada u pripremnom periodu na brzinu vođenja lopte petnaestogodišnjih fudbalera. Sport Mont, 12(40-42), 160-6.

Gardašević, J., Popović, S., \& Bjelica, D. (2016). After preparation period ball shooting accuracy at players U15. In Abstract Book of the 8th Conference for Youth Sport (88), Ljubljana: University of Ljubljana, Faculty of Sport.

Gaurav, V., Singh, M., \& Singh, S. (2010). Anthropometric characteristics, somatotyping and body composition of volleyball and basketball players. Journal of Physical Education and Sports Management 1(3), 28-32.

Gusić, M., Popović, S., Molnar, S., Mašanović, B., Radaković, M. (2017). SportSpecific Morphology Profile: Differences in Anthropometric Characteristics among Elite Soccer and Handball Players. Sport Mont Journal, 15(1): 3-6.

Masanovic, B. (2008). Determination of body composition of athletes. Unpublished Master Thesis. Novi Sad: Faculty of Sport and Physical Education.

Masanovic, B. (2009). Differences of anthropometrical status on top level handball players and non sportsmen. Sport Mont, 6(18-19-20), 569-75.

Masanovic, B. (2015). Anthropological indicators of the proprioceptive training success with football players and students aged 15-16 years. Unpublished Doctoral Dissertation. Novi Sad: University of Novi Sad.

Masanovic, B., \& Vukasevic, V. (2009). Differences of anthropometrical status on basketball and handball players in junior stature. Sport Mont, 6(1819-20), 576-82.

Masanovic, B., Popovic, S., \& Bjelica, D. (2018). Comparative Study of Anthropometric Measurement and Body Composition Between Junior Soccer and Volleyball Players From National League. In Book of Abstracts 15th International Scientific Conference on Transformation Process in Sport "Sport Performance" (58), Podgorica: Montenegrin Sports Academy.

Mašanović, B., Popovic, S. \& Molnar, S. (2009). The differences in some anthropometric characteristics of elite football and basketball players. In Book of Abstracts XLVIII Congress of Anthropological Society of Serbia (87). Prolom Banja: Antrpological Society of Serbia.

Masanovic, B., Vukotic, M., Bjelica, D., \& Popovic, S. (2018). Describing Physical Activity Profile of Older Montenegrin Males Using the International Physical Activity Questionnaire (IPAQ). In Book of Abstracts 15th International Scientific Conference on Transformation Process in Sport "Sport Performance" (61), Podgorica: Montenegrin Sports Academy.

Milanović, D., Jukić, I., Vuleta, D., Šimek, S. \& Šentija D. (2005). Measurement and evaluation of fitness characteristics of Croatian handball players. Zbornik radova Sports Kinetics' 2005 „Scientific Fundaments of Human and Sport Practice", (444-8).

Mišigoj-Duraković, M., Matković, B., \& Medved, R. (1995). Morfološka antropometrija u športu. Morphological anthropometry in sports. Zagreb, Croatia: Fakultet za fizičku kulturu. 
Nikolaidis, P.T., \& Vassilios-Karydis, N. (2011). Physique and body composition in soccer players across adolescence. Asian J Sports Med, 2(2), 75-82.

Popovic, S. (2016). Body Height and its Estimation Utilizing Arm Span Measurements in Montenegrin Adults: National Survey. In Book of Summaries of 11th FIEP European Congress "Anthropological Aspects of Sport Physical Education and Recreation" (5-6), Banjaluka: University of Banjaluka, Faculty of Physical Education and Sport.

Popovic, S. (2017). Local Geographical Differences in Adult Body Height in Montenegro. Montenegrin Journal of Sports Science and Medicine, 6(1), 81-7.

Popovic, S. (2017). Local Geographical Differences in Adult Body Height in Montenegro. Monten. J Sports Sci Med, 6(1), 81-7.

Popovic, S., Akpinar, S., Jaksic, D., Matic, R., \& Bjelica, D. (2013). Comparative Study of Anthropometric Measurement and Body Composition between Elite Soccer and Basketball Players. International Journal of Morphology, 31(2), 461-7.

Popović, S., Bjelica, D., Georijev, G., Krivokapić, D. \& Milašinović, R. (2017). Body height and its estimation utilizing arm span Measurements in Macedonian. The anthropologis, 24(3), 737-45.

Popović, S., Bjelica, D., Molnar, S. Jakšić, D, \& Akpinar, S. (2013). Body height and its estimation utilizing arm span Measurements in serbian adults. Int. J. Morphol., 31(1), 271-9.

Popović, S., Bjelica, D., Tanase, G., \& Milašinović, R. (2015). Body Height and Arm Span in Bosnian and Herzegovinian Adults, Monten. J. Sports Sci. Med. 4(1), 29-36.

Popovic, S., Bjelica, D., Vukotic, M., \& Masanovic, B. (2018). Describing Physical Activity Profile of Older Montenegrin Females Using the International Physical Activity Questionnaire (IPAQ). In Book of Abstracts 15th International Scientific Conference on Transformation Process in Sport "Sport Performance" (60-61), Podgorica: Montenegrin Sports Academy.

Popovic, S., Masanovic, B., Molnar, S., \& Smajic, M. (2009). Determining Body Composition of Top Level Athletes. Teme, 33(4), 1534-49.

Popovic, S., Molnar, S., \& Masanovic, B. (2010). Differences of some anthropometrical characteristics on young football players and boys who don't do any sport. Journal of Antrpological Society of Serbia, 45, 273-9.

Popovic, S., Smajic, M., Joksimovic, A., \& Masanovic, B. (2010). The differences in body composition between football players of different rank competitions. Sport Mont, 8(23-24), 362-7.

Popovic. S., Bjelica, D., Jaksic, D., \& Hadzic, R. (2014). Comparative Study of Anthropometric Measurement and Body Composition between Elite Soccer and Volleyball Players. International Journal of Morphology, 32(1),
267-74.

Ramos-Campo, D.J., Martinez-Sanchez, F., Esteban-Garcia, P., Rubio-Arias, J.A., Bores, C.A., Clemente-Suarez, V.J., \& Jimenez-Diaz, J.F. (2014). Body Composition Features in Different Playing Position of Professional Team Indoor Players: Basketball, Handball and Futsal. Int. J. Morphol., 32(4), 1316-24.

Rogulj, N., Nazor, M., Srhoj, V., \& Božin, D. (2006). Differences between competitively effi cient and less effi cient junior handball players according to their personality traits. Kinesiology, 38(2), 158-163.

Sermaxhaj, S., Popović, S., Bjelica, D., Gardašević, J., \& Arifi, F. (2017). Effect of recuperation with static stretching in isokinetic force of young football players. Journal of Physical Education and Sport, 17(3), 1948-53. doi: 10.7752/jpes.2017.03191

Strel, J. (2006). Correlation of physical characteristics and general endurance: A comparison of 7- to 19-year-old pupils between 1983, 1993 and 2003. Anthropological Notebooks 12(2), 113-28.

Vasiljević, I., Bjelica, D., Popović, S., \& Gardašević, J. (2015). Analysis of nutrition of preschool-age and younger school-age boys and girls. Journal of Physical Education and Sport, 15(3), $426-8$.

Vukasevic, V. (2010). Uporedna analiza morfoloških i motoričkih dimenzija košarkaša prvog i drugog ranga takmičenja srbije i crne gore. Neobjavljena magistarska teza. Beograd: ,'Alfa" BK Univerzitet, Fakultet za menadžment u sportu.

Vukotić, M. (2010). Nivo morfoloških karakteristika, motoričkih i funkcionalnih sposobnosti sportista različitog sportskog usmjerenja. Neobjavljena magistarska teza. Nikšić: Fakultet za sport i fizičko vaspitanje.

Vukotić, M. (2011). Differences of anthropometric characteristic and motor abilities of different sport orientation. Sport Mont, 9(28-29-30), 112-8.

Vukotic, M. (2018). Comparative analysis of antropmtric indicators of sportisis of different soprts guidance. In Book of Abstracts 15th International Scientific Conference on Transformation Process in Sport "Sport Performance" (75-76), Podgorica: Montenegrin Sports Academy.

Vukotić, M., Čorluka, M., Vasiljević, I., \& Bubanja, M. (2018). Differences in the Morphological Characteristics and Body Composition of Handbal Players WHC Levalea in Montenegro and WHC Grude in Bosnia and Herzegovina. J. Anthr. Sport Phys. Educ. 2(2018) 2: 49-53 Original scientific paper DOI: 10.26773/jaspe.180409

Vuleta, D., Nikolić, A., \& Krakan, I. (2011). Razlike između kadeta i mlađih rukometaša antropometrijskim karakteristikama. 20. Ljetnja škola kineziologa republike Hrvatske (110-116), Split: Hrvatski kineziološki savez. 